\title{
Computer use in older adults: Determinants and the relationship with cognitive change over a 6 year episode
}

\author{
Karin Slegers ${ }^{\mathrm{a}, *}$, Martin P.J. van Boxtel ${ }^{\mathrm{b}}$, Jelle Jolles ${ }^{\mathrm{b}}$ \\ ${ }^{a}$ Centre for User Experience Research, K.U. Leuven/IBBT, Parkstraat 45, B-3000 Leuven, Belgium \\ ${ }^{\mathrm{b}}$ Department of Psychiatry and Neuropsychology, School for Mental Health and Neuroscience, Maastricht University, P.0. Box 616, 6200 MD Maastricht, The Netherlands
}

\section{A R T I C L E I N F O}

\section{Article history:}

Available online 7 September 2011

\section{Keywords:}

Computer use

Internet

Elderly

Cognitive aging

\begin{abstract}
A B S T R A C T
Cognitively challenging activities may support the mental abilities of older adults. The use of computers and the Internet provides divergent cognitive challenges to older persons, and in previous studies, positive effects of computer and Internet use on the quality of life have been demonstrated. The present study addresses two research aims regarding predictors of computer use and the relationship between computer use and changes in cognitive abilities over a 6-year period in both younger (24-49 years) and older adults (older than 50 years). Data were obtained from an ongoing study into cognitive aging: the Maastricht Aging Study, involving 1823 normal aging adults who were followed for 9 years. The results showed age-related differences in predictors of computer use: the only predictor in younger participants was level of education, while in older participants computer use was also predicted by age, sex and feelings of loneliness. Protective effects of computer use were found for measures of selective attention and memory, in both older and younger participants. Effect sizes were small, which suggests that promotion of computer activities in older adults to prevent cognitive decline may not be an efficient strategy.
\end{abstract}

() 2011 Elsevier Ltd. All rights reserved.

\section{Introduction}

Cognitive abilities tend to decline with age (Craik \& Salthouse, 2000; van der Elst, van Boxtel, van Breukelen, \& Jolles, 2005; van Hooren et al., 2007). Several studies have suggested that engagement in cognitively challenging activities, such as reading books or newspapers, playing games, making crossword puzzles and listening to the radio or to music, is associated with maintenance or even improvement of cognitive skills and seems to protect against age-related decline of cognitive abilities (Bosma et al., 2002; Christensen et al., 1996; Hultsch, Herzog, Small, \& Dixon, 1999; Verghese et al., 2003; Wilson et al., 2002).

The notion that it may be possible to improve cognitive functioning by promoting the participation of older persons in cognitively challenging activities has become widespread since Swaab introduced his 'use it or lose it' principle (Swaab, 1991), based on his animal research in which he demonstrated that the use of neurons and neuronal networks prolongs the efficiency of central nervous system (CNS) activity. When the notion of 'use it or lose it' is applied to a functional level, this would imply that mental stimulation may counteract the reduced efficiency of higher brain functions that comes with age. Empirical evidence to support this

\footnotetext{
* Corresponding author.

E-mail addresses: Karin.Slegers@soc.kuleuven.be (K. Slegers), Martin.vanBox tel@np.unimaas.nl (M.P.J. van Boxtel), j.jolles@psy.vu.nl (J. Jolles).
}

has been found in animal studies, which have shown that enriched environments, providing a stimulating and challenging habitat, are beneficial to the cognitive functioning of laboratory animals (Frick \& Fernandez, 2003; Milgram, 2003). Also, such findings are consistent with the concept of cognitive reserve in humans, which assumes that individuals with more elaborate cognitive strategies are better protected against symptom onset following brain damage (Robertson \& Murre, 1999; Stern, 2002, 2007).

Using computers and the Internet may provide a cognitive and intellectual challenging activity, which is intrinsically rewarding, because Internet-based services may have particular benefits for older persons (Amichai-Hamburger, McKenna, \& Tal, 2008; Cody, Dunn, Hoppin, \& Wendt, 1999; Tak, Beck, \& McMahon, 2007; White et al., 2002). Moreover, using computers and the Internet may even improve autonomy, because in order to use Internet services such as Web surfing or e-mail, many of the cognitive abilities that are intensively drawn upon, are also essential in everyday functioning. For instance, long-term or procedural memory is required to activate the routines that are necessary to use a computer program, e.g. to launch a Web browser, and to execute specific commands in that browser. Short-term memory, or working memory, is activated to keep track of information already processed or to decide on the next action to take. Executive functions come into play when strategies are made to perform a task efficiently. Visual search, information processing and attentional processes are recruited in order to find relevant cues, to evaluate 
which information on a Web page is relevant within a given context, and to focus on those cues while ignoring or inhibiting irrelevant cues.

Many of the cognitive abilities mentioned above gradually decline with advancing age (Craik \& Salthouse, 2000). On the other hand, it has been shown that using the Internet provides a cognitive challenge to older people, as information technology is often quite unfamiliar to older adults (Docampo Rama, de Ridder, \& Bouma, 2001). Another reason why using the Internet may be a particularly suitable strategy to stimulate older adults to engage in cognitively challenging activities is that Internet-based services may have particular benefits for them with respect to autonomy and everyday functioning (Cody et al., 1999; White et al., 2002). For instance, the World Wide Web facilitates social interaction and communication (Czaja, Guerrier, Nair, \& Landauer, 1993; Mead, Batsakes, Fisk, \& Mykityshyn, 1999; Morrell, Mayhorn, \& Bennett, 2000; Rogers \& Fisk, 2000), and provides means for distant learning and entertainment (Czaja et al., 1993; Mead et al., 1999; White et al., 1999). Also, the Internet provides access to information services (Czaja \& Lee, 2001), and facilitates the execution of many routine tasks (e.g. banking and shopping) (Bouchard Ryan \& Heaven, 1986; Czaja et al., 1993; Rogers \& Fisk, 2000). Finally, it has been argued that computer use can improve self-esteem and satisfaction with life (Jones \& Bayen, 1998; Lawhon, Ennis, \& Lawhon, 1996; Mead et al., 1999; Sherer, 1996). Because of such benefits, using computers and the Internet may be intrinsically rewarding for older adults, which may motivate them to start and keep using such facilities.

When positive effects of long-term computer use on cognitive abilities can be demonstrated, then the promotion of computer use to prevent people from age-related cognitive decline may still be an effective intervention. To date, however, only few attempts have been made to study the impact of computer and Internet use on the cognitive abilities. Several broader studies showed that psychosocial measures, such as self-confidence, loneliness, social interaction, satisfaction with life and depression, improved as a result of learning to use computers and the Internet (Cody et al., 1999; White et al., 2002). A limited number of studies have actually focused on the impact of computer and Internet use on cognitive functioning as the primary outcome. McConatha, McConatha, and Dermigny (1994) showed that, in a small sample $(N=14)$ of long-term care residents aged between 59 and 89, the score in the Mini-Mental State Examination (MMSE; a cognitive screening test), Activities of Daily Living (ADL), and depression scores improved after using an on-line computer service for 6 months. This service consisted of e-mail, access to a digital encyclopedia, bulletin boards, games and other educational and recreational applications. Comparable results were found in a subsequent study, where 29 nursing home residents, aged 50 and older, were divided into a computer training group and a control group (groups were matched in terms of ability to take care of daily needs, cognitive functioning and depression level) (McConatha, McConatha, Deaner, \& Dermigny, 1995). Participants in the training group used the same on-line computer service as had been used in the previous study and participants in the control group participated in regular nursing home recreational and educational activities. After 6 months of using the computer service, participants in the computer-training group improved on MMSE, ADL and depression scores, while the control group remained unchanged. In sum, mainly circumstantial evidence indicates that learning to use a computer and the Internet in later life may have beneficial effects on the cognitive ability of older individuals.

We studied the impact of computer use on cognitive function in a randomized controlled study over a 12 month period (Slegers, van Boxtel, \& Jolles, 2009). Participants in the age between 65 and 75 years, who were randomly assigned to an Intervention group, were compared with three control groups to account for effects of intervention, computer training and interest in computers and the Internet. No effects of computer training and habitual use in daily life were found on several domains of cognitive abilities. Thus, using a computer for 12 months was not an efficient strategy to prevent short-term cognitive decline.

\subsection{Research aims}

At present, no studies are available on the effect of prolonged (i.e. more than 1 year) on self-initiated computer use on cognitive functions. In addition, knowledge about factors that determine the actual use of computers in different age groups is scarce, although such information may be of considerable relevance in the context of intervention. The first research aim of the present study considered predictors of computer use in both younger and older adults. As outlined above, computer use may have particular benefits for older adults. We therefore specifically investigated sociodemographic variables (age, sex, educational level) and indicators of physical and mental functioning as possible determinants of computer use. Health status was considered relevant in this regard because computer and Internet services are especially interesting for individuals who are restricted in their mobility because of health problems. Furthermore, problems with mental health, such as mood problems, may cause individuals to lack initiative to engage in (new) activities that may actually be beneficial to them. Also, a measure of perceived cognitive problems was included. This measure is important in this context because people with low selfefficacy in, for instance, the cognitive domain, have low aspirations (Bandura, 1989) and may therefore be less inclined to start new activities such as using a computer. Finally, two measures of quality of life were included to account for peoples' loneliness and life satisfaction.

The second research aim of this study was to determine the relationship between computer use and changes in cognitive functioning to test the abovementioned notion that engagement in cognitively challenging activities for a long period is associated with maintenance or even improvement of cognitive skills. For this purpose, we used a number of cognitive measures that represent a broad range of cognitive abilities (i.e., verbal memory, speed of information processing, attention, psychomotor ability and cognitive flexibility).

\subsection{Research approach}

In light of the research aims described above, we investigated predictors of computer use and the relationship between computer use and cognitive functioning for both younger (up to 50 years) and older individuals ( 50 years and older) who were administered a questionnaire including several questions about computer and Internet use. The questionnaire included items on the use of computer and Internet applications and some statements on the impact of computer use, so we were also able to study age-related differences with respect to these items. Data from the Maastricht Aging Study (MAAS) were used. MAAS is a large population study involving 1823 healthy participants aged 24-81 years at baseline assessment. The major aim of this longitudinal study concerns biological, medical and psychosocial predictors of cognitive aging. For an overview of the aim, design and population characteristics, see Jolles, Houx, van Boxtel, and Ponds (1995). By using data from MAAS we were able to study computer use and it's predictors on a large population-based sample. Cognitive abilities were measured at several occasions, and therefore we were able to address the potential causality in the relationship between computer use and changes in cognitive functioning better. 
Of interest to the current study were the 6-year and 9-year follow-up measurements in MAAS. The predictors of computer use were studied cross-sectionally at the 9-year follow-up moment. Furthermore, the relationship between computer use and changes in cognitive functioning were studied retrospectively by calculating whether the participants had already been using computers at earlier occasions in this study. We used data from the baseline and second follow-up (after 6 years) test administrations, when extensive cognitive screening was performed. Thus, it was tested whether reported computer use at baseline predicted the performance level on cognitive tests 6 years later.

\section{Methods}

\subsection{Participants and procedure}

Participants in this study were taken from the Maastricht Aging Study (MAAS, for more details of this study and its participants, see Jolles et al. (1995)). They were randomly recruited from a patient register of 15 collaborating general practitioners in the south of the Netherlands. This sample frame is considered to reflect the general population of the region, as all Dutch civilians are obliged to register in a general practice database. All participants were community-dwelling adults who were, at the moment of recruitment, between 24 and 81 years of age. Exclusion criteria were medical conditions known to interfere with normal cognitive functioning and participants were to have a score of 24 or higher on the Mini-Mental State Examination (Folstein, Folstein, \& McHugh, 1975). The study sample was stratified with respect to age (12 groups: $25 \pm 1,30 \pm 1,35 \pm 1, \ldots, 80 \pm 1$ years), sex and level of occupational attainment (two levels). Between 1993 and 1995, 1823 people were assessed with respect to both cognitive and physical measures. Three follow-up assessments took place after 3, 6 and 9 years. At each follow-up, several questionnaires were administered to all participants. Participants of 50 years and older also underwent neuropsychological testing at the first and second follow-up. The younger participants were tested at the second follow-up only. Because of this discrepancy in follow-up frequencies between participants younger and older than 50 years at baseline, collapsing the data of these two groups was not considered a viable option due to potential differences in procedural learning effects. Therefore, the distinction between young and old adults was made at age 50. Moreover, the proportion of computer users in this group of older adults aged 50 and older is reasonably high, while this proportion in older age groups (e.g. $n=6$ in participants above 65 years) is too small to analyze properly.

The 9-year follow-up (January 2003-December 2004) contained only questionnaires, including the questions on computer use. In total, data of 1349 (74\%) participants were collected at the 9-year follow-up. Reasons to step out of the study were death $(n=178)$, health related ( $n=62)$, refusal ('no interest', 'lack of time', experienced burden) $(n=133)$, unreliable test results $(n=5)$ or participants could not be reached or did not specify a reason $(n=96)$.

\subsection{Measures}

\subsubsection{Questions on computer use}

At 9-year follow-up, the questionnaire included several questions on computer use. Participants were asked whether they use a computer, and if so, to indicate the year one started doing this. This indication made it possible to calculate the number of years that participants had been using computers and also whether they had been using a computer already at baseline. Other questions to assess computer use concerned the kind of computer applications that participants used, the way they learned to use a computer, their use of the Internet and their agreement with statements about computer use (the full questionnaire can be found in the Appendix).

\subsubsection{Predictors of computer use}

Both socio-demographic variables and measures of subjective functioning were included to predict computer use. Age, sex and level of education were used as demographical indicators. Level of education was measured on an eight-point scale as used by Statistics Netherlands (de Bie, 1987). The scale ranges from primary education (1) to higher vocational training and university degree (8).

The physical and the mental functioning components of the RAND-36 (Ware, Kosinski, \& Keller, 1994), a 36-item questionnaire on general health and quality of life, were included to measure subjective functional status. Also, a question whether participants were in the past year hindered by problems with their memory or concentration as a measure of subjective cognitive functioning was used. This question was scored on a five-point scale, ranging from "not at all" to "a lot". Finally, as indications of subjective wellbeing, the Loneliness Questionnaire (LQ, De Jong-Gierveld \& Kamphuis, 1986) and the Satisfaction With Life Scale (SWLS, Pavot, Diener, Randall Colvin, \& Sandvik, 1991) were included.

\subsubsection{Computer use as a predictor of cognitive functioning}

To study the relationship between computer use and cognitive performance, two dummy variables were created to predict cognitive performance at the 6-year follow-up: "computer use at baseline" and "start with computer use after baseline", using the participants who indicated not to use a computer at the 9-year follow-up as the reference group. Of the core cognitive tests that are used in MAAS, five tests were included in this study to represent the most important domains of cognitive functioning.

The Visual Verbal Learning Test (VVLT) van der Elst et al., 2005 was used to measure verbal memory. In this test, fifteen monosyllabic, low-associative words are successively presented. After the presentation, participants were asked to recall as many words as possible without any time or order constraint (immediate recall). This procedure was repeated five times. Twenty minutes after the recall of the fifth trial, the participants were once more asked to recall as many words as possible (delayed recall). The score in the first trial of the immediate recall, the sum of the scores in the first three trials and the delayed recall score were used for this study.

The Letter-Digit Substitution Test (LDST) van der Elst, van Boxtel, van Breukelen, \& Jolles, 2006 was used to measure the speed of processing general information. This test is a modification of the Symbol-Digit Modalities Test (Lezak, 1995). A code is provided at the top of a sheet of paper that couples the numbers 19 with random letters. Participants were asked to fill in on the rest of the sheet as many as possible corresponding numbers in boxes that contained only letters in $90 \mathrm{~s}$.

The Concept Shifting Test (CST) Van der Elst, van Boxtel, van Breukelen, \& Jolles, 2006a was used to measure cognitive flexibility. This test consists of three sheets of paper with 16 small circles that are grouped in a larger circle. On the first sheet, numbers appear in the small circles in a fixed random order. Participants were asked to cross out these numbers in the right order as fast as possible. On the second sheet, letters appear in the circles. On the third sheet, participants must alternate between numbers and letters. The difference between the score for the third sheet and the mean of the scores for the first and second sheets was used as an estimate of the slowing due to the shifting between two concepts (numbers and letters), i.e. cognitive flexibility.

The Stroop Colour Word Test (SCWT) Van der Elst, van Boxtel, van Breukelen, \& Jolles, 2006b was used as a measure of selective 
attention and susceptibility to interference. The test contains three cards displaying a hundred stimuli each: color names, colored patches and color names printed in incongruously colored ink. The time needed to read (first) or to name colors (second and third card) of each of the cards was recorded. The difference between the score for the third card and the mean of the scores for the first and second cards (the interference score) was used as a measure of the capacity to inhibit a habitual response (reading the word), which reflects selective attention.

To measure psychomotor speed, finally, the Motor Choice Reaction Time test (MCRT) Houx \& Jolles, 1993 was included. This test is administered with a six-button panel, containing one red button and five white buttons, laid out in a semicircle around and above the red button. The participants were asked to hold down the red button with the index finger of the preferred hand. As soon as one of the white buttons was lit, the participants were to release the red button and then press the lit button (or a button adjacent to it) as quickly as possible. After this, the red button had to be held down again. The MCRT involved three conditions. In the first condition (simple reaction time), only the upper white button was lit. In the second condition (choice reaction time), one of the three upper buttons was lit. In the third condition (incompatible choice reaction time), one of the three upper buttons was lit, however, the button immediately to the right of the lit button was to be pressed. Two variables were used for this study. Firstly, the difference between the median response times of the second and the first condition was used as an indication of response selection. Secondly, a measure of inhibition of a prepotent response (Kornblum, Hasbroucq, \& Osman, 1990) was provided by the difference between the median times needed in the third and the second condition.

\subsection{Statistical analyses}

Statistical analyses were performed with SPSS version 11 for Apple Macintosh. Alpha level was set to .05. To exploratory study differences between younger (up to 50 years) and older (50 years and above) participants with respect to the questions on computer use, both unpaired $t$-tests and Chi-square tests were performed.

\subsubsection{Cross-sectional predictors of computer use}

Logistic regression analyses were performed to predict computer use in both age groups. Also, linear regression analyses were performed to predict the number of years participants had been using computers in both age groups. Chronological age, level of education and sex were entered in the first step. In the second step, the physical and mental component of the RAND-36, hindrance of problems with remembering, memory and concentration, the Loneliness Questionnaire and the Satisfaction with Life Scale were included.

\subsubsection{Predictors of longitudinal cognitive performance}

Linear regression analyses were used to study the relationship between computer use and cognitive changes over a 6 year period. For all dependent variables, performance on the cognitive tests at the 6-year follow-up, the same basic regression model was used. In the first step, age, sex and level of education were entered, at step two, baseline performance on the particular cognitive test, and at step three, the two dummy variables coding for "computer use at baseline" and "start to use computers after baseline".

For all analyses two age groups were defined: the young group including the participants who were younger than 50 years at baseline, and the old group, including the participants who were 50 years or older at this time. Both the cross-sectional regression analyses and the longitudinal regression analyses were performed for each age group separately.

\section{Results}

A total of 1256 people reliably indicated if they already used computers at baseline. The cross-sectional comparisons and the regression analyses were performed with data of complete cases. Comparisons concerning the duration of computer use and the longitudinal regression analyses were done with data of the 1256 participants of whom the start date of computer use was available.

\subsection{Age differences in computer use}

Both at baseline $\left(\chi^{2}(1, N=1256)=189.87, p<.01\right)$ and at the 9-year follow-up $\left(\chi^{2}(1, N=1323)=385.23, p<.01\right)$, more participants in the younger group used a computer than in the older group (for the exact numbers and percentages, see Table 1). Also, in the younger group there were relatively more participants who started using a computer in the period between baseline and the 9-year follow-up $\left(\chi^{2}(1, N=1256)=47.95, p<.01\right)$. In the group of computer users, participants in the younger age group had been using computers on average for a longer time (10.3 years) compared to participants in the older age group (7.2 years) $(t(750)=5.39, p<.01)$, and younger users also contacted more people and organizations via e-mail $((t(621)=3.65, p<.01)$ than older users (21 vs. 12.7). In the younger group of computer users, more participants had access to the Internet $\left(\chi^{2}(1, N=821)=31.67\right.$, $p<.01)$ than in the older group (92.8\% vs. $72.8 \%)$. No difference was found with respect to the number of hours per week participants reported to use the Internet: $6.77 \mathrm{~h}$ in the young group vs. $5.55 \mathrm{~h}$ in the old group.

Some differences were noted with respect to how people learned to use computers. It was found that more younger (58.1\%) than older (40.1\%) users taught themselves to use a computer and that more older (36.2\%) than younger (24.1\%) users preferred a book to learn to use a computer. No differences were found between the percentages of younger and older users with respect

Table 1

Number of participants who use a computer at baseline and at the 9-year follow-up, by age (<50 vs. 50+), sex and level of education (low vs. high).

\begin{tabular}{|c|c|c|c|c|c|c|}
\hline \multirow[b]{2}{*}{ Level of education } & \multicolumn{3}{|l|}{ Young } & \multicolumn{3}{|l|}{ Old } \\
\hline & Male & Female & Total & Male & Female & Total \\
\hline \multicolumn{7}{|l|}{ Baseline } \\
\hline Low & $26(26.3 \%)$ & $21(19.9 \%)$ & $47(19.9 \%)$ & $12(7.3 \%)$ & $4(1.6 \%)$ & $16(4.0 \%)$ \\
\hline High & $165(71.7 \%)$ & $96(49.0 \%)$ & $261(61.3 \%)$ & $42(35.3 \%)$ & $7(10.0 \%)$ & $49(25.9 \%)$ \\
\hline Total & $191(58.1 \%)$ & $117(35.3 \%)$ & $308(46.5 \%)$ & $54(19.0 \%)$ & $11(3.5 \%)$ & $65(10.9 \%)$ \\
\hline \multicolumn{7}{|l|}{ 9-year follow-up } \\
\hline Low & $82(76.6 \%)$ & $89(62.7 \%)$ & $171(68.7 \%)$ & $49(28.5 \%)$ & $40(16.4 \%)$ & $89(21.4 \%)$ \\
\hline High & $242(98.0 \%)$ & $200(93.0 \%)$ & $442(95.7 \%)$ & $78(62.4 \%)$ & $39(54.9 \%)$ & $117(59,7 \%)$ \\
\hline Total & $324(91.5 \%)$ & $289(81.0 \%)$ & $613(86.2 \%)$ & $127(42.8 \%)$ & $79(25.1 \%)$ & $206(33.7 \%)$ \\
\hline
\end{tabular}


Table 2

Percentages of participants in the young and old age groups that use each of the computer and Internet applications and differences between the groups.

\begin{tabular}{lrrrrrr}
\hline & Young & Old & df & $N$ & \multicolumn{1}{c}{$X^{2}$} & Sig. \\
\hline Computer & & & & & & \\
Word processor & 82.4 & 71.0 & 1 & 820 & 12.27 & $<0.01$ \\
Internet browser & 83.5 & 61.4 & 1 & 820 & 44.22 & $<0.01$ \\
E-mail & 80.8 & 68.6 & 1 & 820 & 13.18 & $<0.01$ \\
Games & 41.6 & 51.9 & 1 & 819 & 6.69 & $<0.01$ \\
Calculating & 33.6 & 20.4 & 1 & 819 & 12.76 & $<0.01$ \\
Multimedia & 26.1 & 14.1 & 1 & 819 & 12.56 & $<0.01$ \\
Graphic & 14.8 & 11.7 & 1 & 819 & 1.30 & 0.25 \\
Internet & & & & & & \\
Searching information on & & & & & & \\
$\quad$ Events & 28.5 & 14.1 & 1 & 819 & 17.20 & $<0.01$ \\
$\quad$ Travel/public transportation & 53.5 & 43.7 & 1 & 819 & 5.95 & 0.02 \\
$\quad$ Health & 24.1 & 18.9 & 1 & 819 & 2.38 & 0.12 \\
$\quad$ Opening hours & 19.2 & 7.8 & 1 & 819 & 14.86 & $<0.01$ \\
Games & 18.0 & 11.1 & 1 & 819 & 6.51 & 0.01 \\
Newsgroups & 10.9 & 6.8 & 1 & 819 & 2.96 & 0.09 \\
Chatting & 8.0 & 4.4 & 1 & 819 & 3.08 & 0.08 \\
Reading news & 33.4 & 20.9 & 1 & 819 & 11.54 & $<0.01$ \\
Shopping & 20.2 & 10.7 & 1 & 819 & 9.60 & $<0.01$ \\
\hline
\end{tabular}

to taking a computer course ( $50.7 \%$ vs. $51 \%$ ) and to learning from friends or family $(43.5 \%$ vs. $37.4 \%)$. Also, there were differences in the applications younger and older participants indicated to use (see Table 2). More users in the older group indicated to use their computer to play games. Relatively more participants in the younger group used all other applications, except graphic applications, where no differences were apparent. More younger than older computer users also indicated to use the Internet for searching information about events, travel and opening hours, for reading news and for shopping. Again, in the older group of computer users, the proportion of participants who indicated to use the Internet for playing games was larger than in the younger group (Table 2).

Finally, some age differences were found with respect to the statements on the impact of computer use (Table 3). Older users agreed more (or disagreed less) with the statements that using computers and the Internet provides a possibility to train their brain, to deal with everyday problems, and to improve autonomy. On the other hand, they also found working with computers and the Internet more difficult than younger users.

\subsection{Predictors of computer use}

For both age groups, the first step in the logistic regression analysis with computer use as the dependent variable predicted a significant percentage of the cases correctly $(93.3 \%$ and $79.5 \%$ in the
Table 4

Unstandardized coefficients (B) and standard errors (SE) in the final model for computer use at the 9-year follow-up.

\begin{tabular}{llllll}
\hline & B & S.E. & Wald & Sig. & Exp(B) \\
\hline Young & & & & & \\
Age & -0.07 & 0.06 & 1.39 & 0.24 & 0.94 \\
Education & 0.69 & 0.17 & 15.81 & .00 & 2.00 \\
Sex & -0.48 & 0.46 & 1.13 & 0.29 & 0.62 \\
Physical functioning & 0.02 & 0.04 & 0.26 & 0.61 & 1.02 \\
Mental functioning & 0.04 & 0.04 & 1.32 & 0.25 & 1.04 \\
Loneliness & -0.02 & 0.04 & 0.27 & 0.61 & 0.98 \\
Satisfaction with life & 0.00 & 0.04 & 0.00 & 1.00 & 1.00 \\
Memory/concentration & 0.41 & 0.36 & 1.32 & 0.25 & 1.51 \\
Old & & & & & \\
Age & -0.13 & 0.01 & 145.56 & 0.00 & 0.88 \\
Education & 0.65 & 0.06 & 105.43 & 0.00 & 1.91 \\
Sex & -0.89 & 0.19 & 22.75 & 0.00 & 0.41 \\
Physical functioning & 0.02 & 0.01 & 1.77 & 0.18 & 1.02 \\
Mental functioning & -0.02 & 0.01 & 1.62 & 0.20 & 0.98 \\
Loneliness & -0.03 & 0.02 & 3.99 & 0.05 & 0.97 \\
Satisfaction with life & 0.02 & 0.02 & 0.71 & 0.40 & 1.02 \\
Memory/concentration & 0.05 & 0.12 & 0.18 & 0.67 & 1.05 \\
\hline
\end{tabular}

young and old age groups, respectively). After this step, the step including the subjective measures of autonomous functioning and wellbeing, did not predict an additional significant proportion of the cases correctly in both age groups.

Table 4 shows the unstandardized regression coefficients of the separate predictors in the final step of the regression models for both age groups. In the younger group, only level of education significantly predicted computer use; participants with higher levels of education showed a higher tendency to use computers. In the older age group, next to age, sex and level of education, the score on the loneliness questionnaire significantly predicted computer use. That is, in this age group, participants who are younger and male, who have higher levels of education and who feel less lonely were more inclined to use computers.

Next to computer use, linear regression analyses were done to predict the number of years participants had been using computers. In both age groups, none of the two steps in the model explained significant proportions of variance. Also, in the final step of these regression models, not one of the separate predictors were found to significantly predict the number of years of computer use.

\subsection{Computer use and changes in cognitive performance}

For both age groups, the first step in the model, including age, sex and level of education, explained significant proportions of variance of all the cognitive measures (ranging from $7.3 \%$ to $17.3 \%$ in the younger group and $7.8-32.6 \%$ in the older group) except for the

Table 3

Means (SD) of and differences between the young and old age groups with respect to their agreement with the statements on computer and Internet usage.

\begin{tabular}{|c|c|c|c|c|c|c|}
\hline & & Young & Old & df & $t$ & Sig. \\
\hline 1 & Train y our brain & $3.23(0.82)$ & $3.49(0.71)$ & 809 & -3.94 & $<0.01$ \\
\hline 2 & Dealing with everyday problems & $2.71(0.88)$ & $2.91(0.76)$ & 808 & -2.81 & $<0.01$ \\
\hline 3 & Autonomy & $3.25(0.89)$ & $3.40(0.81)$ & 807 & -2.22 & 0.03 \\
\hline 4 & Dealing with other technologies & $3.38(0.78)$ & $3.38(0.83)$ & 801 & 0.04 & 0.97 \\
\hline 5 & Quality of life & $3.22(0.92)$ & $3.13(1.00)$ & 802 & -1.11 & 0.27 \\
\hline 6 & Internet is difficult & $2.43(0.94)$ & $3.16(0.93)$ & 808 & -9.55 & $<0.01$ \\
\hline 7 & Changed my life & $2.67(1.03)$ & $2.61(1.00)$ & 805 & 0.79 & 0.43 \\
\hline 8 & Increase regular contacts & $2.95(1.06)$ & $2.89(0.99)$ & 803 & 0.68 & 0.5 \\
\hline 9 & Meet new people & $2.93(1.04)$ & $2.92(0.93)$ & 801 & 0.43 & 0.67 \\
\hline 10 & Not for $\mathrm{m} \mathrm{e}$ & $1.84(0.93)$ & $1.95(0.96)$ & 804 & -1.49 & 0.14 \\
\hline
\end{tabular}

Note: For the exact phras ing of these questions, see the questionnaire in Appendix A. 
Table 5

Unstandardized coefficients (B) and standard errors (SE) in the final model for each of the cognitive measures.

\begin{tabular}{|c|c|c|c|c|c|c|c|c|c|c|c|c|c|c|c|c|}
\hline & \multicolumn{2}{|l|}{ LDST } & \multicolumn{2}{|l|}{ CST } & \multicolumn{2}{|l|}{ SCWT } & \multicolumn{2}{|c|}{ VVLT trial 1} & \multicolumn{2}{|c|}{ WLT total } & \multicolumn{2}{|c|}{ WLT dr } & \multicolumn{2}{|c|}{ MCRT rs } & \multicolumn{2}{|c|}{ MCRT inhib. } \\
\hline & B & SE & $\mathrm{B}$ & SE & B & SE & B & SE & B & SE & B & SE & $\mathrm{B}$ & SE & B & SE \\
\hline \multicolumn{17}{|l|}{ Young } \\
\hline Age (years) & -0.06 & $0.03^{*}$ & 0.14 & $0.04^{* *}$ & 0.12 & $0.05^{* *}$ & -0.04 & $0.01^{* *}$ & -0.07 & $0.02^{* *}$ & -0.02 & 0.01 & -0.19 & 0.17 & 1.03 & $0.24^{* * *}$ \\
\hline Education (1-8) & 0.31 & $0.14^{*}$ & -0.60 & $0.18^{* * *}$ & -0.65 & $0.24^{* *}$ & 0.11 & $0.05^{*}$ & 0.41 & $0.13^{* * *}$ & 0.18 & $0.06^{* *}$ & 0.06 & 0.86 & -0.35 & 1.18 \\
\hline Sex & 0.62 & 0.44 & 0.10 & 0.54 & -0.97 & 0.75 & 0.20 & 0.16 & 0.81 & $0.38^{*}$ & 0.56 & $0.18^{* *}$ & 2.79 & 2.64 & 2.88 & 3.65 \\
\hline Baseline score & 0.86 & $0.03^{* *}$ & 0.28 & $0.04^{* *}$ & 0.57 & $0.03^{* *}$ & 0.43 & $0.05^{* *}$ & 0.54 & $0.04^{* *}$ & 0.50 & $0.04^{* *}$ & 0.19 & $0.04^{* *}$ & 0.46 & $0.04^{* *}$ \\
\hline PC use (yes/no) & 0.39 & 0.77 & -0.16 & 0.94 & -3.16 & $1.28^{*}$ & 0.72 & $0.27^{* *}$ & 1.14 & 0.64 & 0.00 & 0.30 & -1.82 & 4.57 & -7.40 & 6.27 \\
\hline Start PC use (yes/no) & 0.79 & 0.71 & -0.32 & 0.87 & -2.52 & $1.18^{*}$ & 0.44 & 0.25 & 1.16 & 0.59 & 0.19 & 0.28 & -4.37 & 4.23 & -5.98 & 5.81 \\
\hline \multicolumn{17}{|c|}{ Old } \\
\hline Age (years) & -0.19 & $0.03^{* *}$ & 0.27 & $0.08^{* *}$ & 0.55 & $0.10^{* *}$ & -0.05 & $0.01^{* *}$ & -0.13 & $0.03^{* *}$ & -0.04 & $0.01^{* *}$ & -0.47 & 0.29 & 1.08 & $0.48^{*}$ \\
\hline Education (1-8) & 0.36 & $0.15^{* *}$ & -0.76 & $0.36^{*}$ & -0.42 & 0.44 & 0.19 & $0.05^{* *}$ & 0.42 & $0.13^{* *}$ & 0.14 & $0.07^{*}$ & 1.21 & 1.29 & -0.34 & 2.03 \\
\hline Sex & -0.59 & 0.48 & 2.53 & $1.16^{*}$ & -3.76 & $1.45^{*}$ & 0.21 & 0.16 & 0.49 & 0.43 & 0.36 & 0.22 & -3.28 & 4.28 & -8.67 & 6.77 \\
\hline Baseline score & 0.84 & $0.03^{* *}$ & 0.40 & $0.05^{* *}$ & 0.77 & $0.04^{* *}$ & 0.29 & $0.05^{* *}$ & 0.55 & $0.04^{* *}$ & 0.65 & $0.04^{* *}$ & 0.27 & $0.04^{* *}$ & 0.56 & $0.05^{* *}$ \\
\hline PC use (yes/no) & 1.09 & 0.87 & -1.98 & 2.09 & -2.54 & 2.60 & 0.16 & 0.30 & 0.05 & 0.77 & 0.32 & 0.38 & 1.04 & 7.56 & -9.62 & 11.91 \\
\hline Start PC use (yes/no) & 0.47 & 0.63 & 0.09 & 1.51 & -3.70 & $1.88^{*}$ & 0.47 & $0.21^{*}$ & 1.21 & $0.55^{*}$ & 0.44 & 0.27 & 5.09 & 5.49 & -6.61 & 8.69 \\
\hline
\end{tabular}

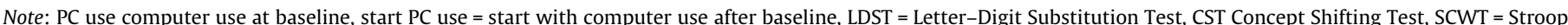

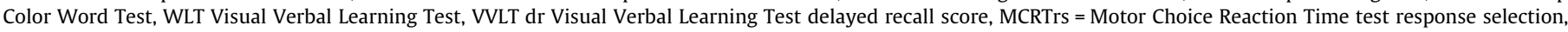
MCRT inhib $=$ Motor Choice Reaction Time test inhibition score.

* Significant at $p<.05$.

*** Significant at $p<.01$.

response selection measure of the MCRT. The second step, baseline performance on the particular task, explained significant additional proportions of variance for all of the measures in both groups (ranging from $4.6 \%$ to $34.3 \%$ in the younger group and $4.8-33.2 \%$ in the older group). The final step in the model, including the two dummy variables of computer use, only explained additional proportions of variance in the youngest age group on the SCWT interference score $(0.6 \%)$ and on the first trial of the VVLT (1.0\%).

Table 5 shows the unstandardized regression coefficients of the separate predictors in the final step of the regression models for both age groups. Computer use was a significant predictor of the SCWT interference score (computer users showed better scores) and of the first trial of the VVLT (again, computer users showed better scores) albeit in the youngest age group only. Participants who started to use computers after the baseline assessment performance showed better SCWT interference scores (both age groups), better scores on the first trial of the VVLT (in the older group only) and on the total score of the VVLT (in the older group only). The effect sizes of these significant regression coefficients (partial $\eta^{2}$ ) range from .007 to .012 . That is, the proportion variance that is uniquely explained by computer use is $0.7-1.2 \%$.

\section{Discussion}

The two main research aims of the present study concerned predictors of computer use in younger and older individuals and the relationship between computer use and changes in cognitive functions in a 6-year period. Before discussing the results with respect to these aims, we first consider age-related differences in the use of computer and Internet applications, and participants' opinions about a number of computer and Internet-related statements.

The differences with respect to the actual use of computers were in line with our expectations, i.e. the proportion of younger participants using a computer was larger: younger computer users contacted a larger number of people through e-mail, and the proportion of computer users with access to the Internet was also larger in the younger group. While older adults used their computers as much as younger adults for Internet-related activities, some differences were found with respect to the applications that were used. Overall, both for computer and Internet applications, older adults tended to use their computers more for playing games than younger adults. All other applications were used by proportionally more younger adults. This may be explained by the fact that in the younger group probably more individuals use computers and the Internet for work or study-related activities compared with the older group.

The results of the computer statements showed that the older computers users agree more with the notion that computer use has a positive effect on autonomy and cognition-related issues. That is, they are more convinced that the notion that using computers and the Internet prevents people from cognitive decline and improves autonomy and everyday functioning is true. The difference between older and younger computer users with respect to this beneficial impact of computers and the Internet may be due to the fact that learning to use computers is new to older adults and that this requires quite an investment, both in time and in effort. For younger users, on the other hand, computers and Internet have become a part of their everyday activities much more gradually, for instance via school or work, and is much more essential for them. For older adults, on the other hand, using a computer is less common and provides more an enrichment to their common activities and may thus be considered a means of assistance with everyday autonomy. Moreover, it may be speculated that this is one of the reasons for older adults to start using a computer, while younger users are more or less obliged to use computers for school or work related activities.

The first research aim of the present study was whether predictors of computer use differ with respect to age. It was found that in the older group individuals who are younger, who are male, who have a higher level of education and who feel less lonely showed a higher tendency to start using computers. In younger people, only individuals with a higher level of education showed this higher tendency. These results demonstrate that for older adults there are more factors that drive individuals to use computers. That means, to motivate older adults to use computers, the factors age, sex, level of education and whether someone feels lonely need to be considered. For instance, such campaigns could be especially designed to appeal individuals who feel lonely. By taking these factors into account, older individuals who might not be inclined to start using a computer by themselves may be persuaded to do so. As a result these individuals can also profit from computer and Internet services that may improve their autonomous functioning. 
The second research aim of the present research was to study the relationship between computer use and cognitive changes. The results showed that younger computer users, compared with younger non-users, showed better Stroop interference scores and better scores on the first trial of the VVLT, corrected for baseline test performance. The same analyses showed that older individuals who started to use computers in the 6 year period between baseline and follow-up performed better on Stroop interference on the first trial of the VVLT and the VVLT total score. In younger adults, starting to use computers was related to better Stroop interference scores. With respect to the original research aim, this implies that computer use is indeed related to a differential change in cognitive abilities. More specifically, using computers seems to protect individuals from declines in selective attention and memory. It has to be noted here, however, that the size of this protective effect is very small and that causal inferences are difficult to make from these data.

The difference in the protective effect of computer use between younger and older adults is mainly that in younger adults, effects of both computer use and of starting to use computers were found, while in older adults only effects of starting to use computers were found. This difference may be explained in part by the fact that the proportion of computer users at baseline in the older group is much lower $(10.9 \%)$ than in the younger group (46.5\%) and may therefore be related to statistical power. Also, the increase in computer users between baseline and the 9-year follow-up (which reflects the number of participants who start to use computers), is much higher in the older group: more than three times as much older individuals at the 9-year follow-up use computers than at baseline, compared with almost twice as much individuals in the younger group. As a result of this, on top of the abovementioned fact of a lower proportion of computer users at baseline in the older group, the effect of the predictor "start to use a computer" may be larger than the effect of "computer use at baseline".

The finding that computer use is related to changes in cognitive abilities are not in line with the results of our randomized controlled intervention study, which demonstrated no effects of 12month computer and Internet use on cognitive changes. The very small number of studies who did found relationships between computer use and measures of cognition in intervention studies (McConatha et al., 1994, 1995) did not use such specific measures of cognitive ability as were used in the present study so it is not possible to compare the results. The differences in findings between our intervention study and the present findings may have several causes. First, the period of computer use of the two studies is different. It could be speculated that 1 year of computer use is not enough to cause changes in cognitive functioning, while 6 years of computer use does yield such changes. However, 12 months does seem to be long enough to detect differential improvement, as is supported by other cognitive intervention studies with similar or shorter follow-up durations (Ball et al., 2002; Kliegl, Smith, \& Baltes, 1989; Schaie \& Willis, 1986; Stigsdotter \& Backman, 1995).

Another difference regards the way participants initiated their computer use. In the present study, computer use was self-initiated, while in intervention studies participants respond to an advertisement or invitation and are provided with a computer. As a result, individuals may have differed in their motivation to use computers. However, differences in motivation should be reflected in differences in the amount of computer use, which could not be confirmed as the participants in the Intervention Group of our intervention study used the Internet with an average of $6.51 \mathrm{~h}$, compared with $6.77 \mathrm{~h}$ of the young group and $5.55 \mathrm{~h}$ of the older group in the present study.

A third and final explanation of the differences in findings concerns the number of participants, and thus again, of power. As intervention studies are quite intensive, both with respect to financial and time issues, the number of participants is usually much smaller than in longitudinal studies into determinants of, in this case, cognitive aging. Because of the large number of participants in the Maastricht Aging Study, the power to detect relatively small effects is quite high, while intervention studies are usually designed to detect medium sized effects. This is supported by the fact that the amounts of explained variance of the final step in the regression model with computer use and starting to use computers in it is quite small and only significant in the younger group. The effect sizes of computer use and starting to use computers in the final step of the model for both age groups are also quite small. In short, based on the present study using a very large group of participants representative of the normal population and earlier studies, including a controlled, randomized intervention study in a relatively large group of older adults, it seems likely that stimulating older adults to use computers and the Internet may yield some effects on cognitive abilities, but that only minor effect sizes are to be expected. Therefore, we consider the promotion of computer use in order to boost cognitive functions not an effective strategy.

A limitation of longitudinal studies in general and therefore also of the present study concerns attrition. In this case, $26 \%$ of the participants who started with MAAS either dropped out of the study, or were unavailable for the 9-year follow-up. Differences in neuropsychological performance between dropouts and participants who stay in the study are a common finding in studies with a longitudinal design (Cooney, Schaie, \& Willis, 1988). Also in MAAS one of the predictors of attrition between baseline and the 3-year follow-up was found to be poorer performance on the baseline cognitive tests (van Beijsterveld et al., 2002). As a result, the participants who were still available for follow-up after 9 years, and whose computer usage data was known, represent a selected group of the original participants, which may have biased the results. However, as was mentioned above, dropouts tend to perform worse on the neuropsychological tests used in this study, so the attrition probably caused an underestimation of the differences between computer users and non-users.

In conclusion, the results of the present study show that predictors of computer use in older adults do not exactly match those in younger adults. This implies that programs aimed at promoting computer use in older adults should take such predictors into consideration. More specifically, such programs should aim at women, older and lower-educated individuals and individuals who feel lonely. Regarding the relationship between computer use and changes in cognitive abilities, a small protective effect of computer use on selective attention and memory processes was found in both younger and older adults. However, this effect was too small to conclude that promoting computer use to support cognitive functions and autonomy is an efficient intervention strategy. 


\section{Appendix A}

1. Do you ever use a computer?

$\square$ Yes, I own a computer

$\square$ Yes, I can use a computer, but it is not my own (e.g. at friends/family)

$\square \quad$ No (proceed with question 8)

If you have answered 'yes', since when have you been using computers? Since L____l_| (fill in a year)

2. What do you use your computer for? You may tick mulitple options.
$\square$ Word processing (e.g. writing letters)
$\square$ Surf the Internet
$\square \quad$ E-mail
$\square$ Games
$\square \quad$ Spreadsheets (e.g. administration)
$\square$ Multimedia (e.g. audio/video applications)
$\square$ Graphical applications (e.g. drawing, designing)
$\square$ Something else:

3. How did you learn to use a computer? You may tick multiple options.
$\square \quad$ I followed a course
$\square \quad$ I learned from friends/family
$\square \quad$ I taught myself
$\square \quad$ I learned by using a book

4. Do you have Internet access?

$\square \quad$ Yes

$\square \quad$ No (proceed with question 8)

5. Please indicate how often you have used the Internet in the past month. You may only tick one option.

$\square$ More than once a day, |_|_| hours per day

$\square$ More than once a week, |_l_ hours per week

$\square$ More than once a month, |_|_| hour per month

$\square \quad$ I do not use the Internet proceed with question 8)

6. What do you use the Internet for? You may tick multiple options.

- Search information on:

My hobbies:

Events 
Travel

Health

Opening hours

Other information:

Games

\section{Visiting newsgroups}

Chatting with other people

Reading the news

\section{Shopping}

Something else:

7. When you use e-mail services, please indicate the number of people and organizations you contact via e-mail on average. | people/organizations

8. Do you agree with the following statements (on a scale ranging from 1 (I fully disagree) to 5 (I fully agree))?

- $\quad$ Learning to use computer and Internet facilities makes it possible to train your brain and keep it in good shape...

- $\quad$ By using computer and Internet facilities one can deal better with everyday problems

- $\quad$ By using computer and Internet facilities one can stay independent for a longer time.

- $\quad$ By using computer and Internet facilities one can deal better with other types of technology.....

- Computer and Internet facilities contribute to the quality of life.

- Working (or learning to work) with computers and the Internet is difficult..

- Computers and the Internet have changed my life

- Computers and the Internet increase the number of people one keeps in contact with regularly.

- Because of the possibilities provided by computers and the Internet one can meet new people more easily.......

- Computers are not meant for me.

\section{References}

Amichai-Hamburger, Y., McKenna, K. Y. A., \& Tal, S. (2008). E-empowerment: Empowerment by the Internet. Computers in Human Behaviour, 24, 1776-1789.

Ball, K. Berch, D. B. Helmers, K. F. Jobe, J. B., Leveck, M. D., Marsiske, M., et al. (2002). Effects of cognitive training interventions with older adults: A randomized controlled trial. Jama, 288, 2271-2281.

Bandura, A. (1989). Regulation of cognitive processes through perceived selfefficacy. Developmental Psychobiology, 25, 729-735.

Bosma, H., van Boxtel, M. P., Ponds, R. W., Jelicic, M., Houx, P., Metsemakers, J., et al (2002). Engaged lifestyle and cognitive function in middle and old-aged, nondemented persons: A reciprocal association? Z Gerontol Geriatr, 35, 575-581.

Bouchard Ryan, E., \& Heaven, R. K. B. (1986). Promoting vitality among older adults with computers. Activities, Adaptation and Aging, 8, 15-30.

Christensen, H., Korten, A., Jorm, A. F., Henderson, A. S., Scott, R., \& Mackinnon, A. J. (1996). Activity levels and cognitive functioning in an elderly community sample. Age Ageing, 25, 72-80.
Cody, M. J., Dunn, D., Hoppin, S., \& Wendt, P. (1999). Silver surfers: Training and evaluating Internet use among older adult learners. Communication Education, 48, 269-286.

Cooney, T. M., Schaie, K. W., \& Willis, S. L. (1988). The relationship between prior functioning on cognitive an personality dimensions and subject attrition in longitudinal research. Journal of Gerontology, 43, 12-17.

Craik, F. I. M., \& Salthouse, T. A. (2000). The handbook af aging and cognition (second ed.). Mahwah, NJ: Erlbaum.

Czaja, S. J., Guerrier, J. H., Nair, S. N., \& Landauer, T. K. (1993). Computer communication as an aid to independence for older adults. Behaviour $\mathcal{E}$ Information Technology, 12, 197-207.

Czaja, S. J., \& Lee, C. C. (2001). The internet and older adults: Design challenges and opportunities. In N. Charness, D. C. Parks, \& B. A. Sabel (Eds.), Communication, technology and aging (pp. 60-78). New York (NY): Springer Publishing Company.

de Bie, S. E., 1987. Standaardvragen: Voorstellen voor uniformering van vraagstellingen naar achtergrondkenmerken en interviews. Leiden, The 
Netherlands: Leiden University Press [Standard questions 1987: proposal for uniformization of questions regarding background variables and interviews].

De Jong-Gierveld, J., \& Kamphuis, F. H. (1986). The development of a rash-type loneliness scale. Applied Psychological Measurement, 9, 289-299.

Docampo Rama, M., de Ridder, H., \& Bouma, H. (2001). Technology generation and age in using layered user interfaces. Gerontechnology, 1, 25-40.

Folstein, M. F., Folstein, S. E., \& McHugh, P. R. (1975). Mini-mental state: A practical method for grading the cognitive state of patients for the clinician. Journal of Psychiatric Research, 12, 189-198.

Frick, K. M., \& Fernandez, S. M. (2003). Enrichment enhances spatial memory and increases synaptophysin levels in aged female mice. Neurobiology of Aging, 24, 615-626.

Houx, P. J., \& Jolles, J. (1993). Age-related decline of psychomotor speed: Effects of age, brain health, sex and education. Perceptual and Motor Skills, 76, 195-211.

Jolles, J., Houx, P. J., van Boxtel, M. P. J., \& Ponds, R. (Eds.). (1995). Maastricht aging study: Determinants of cognitive aging. Maastricht, The Netherland: Neuropsych Publishers.

Hultsch, D. F., Herzog, C., Small, B. J., \& Dixon, R. A. (1999). Use it or lose it: Engaged lifestyle as a buffer of cognitive decline in aging? Psychology and Aging, 14, 245-263.

Jones, B. D., \& Bayen, U. J. (1998). Teaching older adults to use computers: Recommendations based on cognitive aging research. Educational Gerontology, 24, 675-689.

Kliegl, R., Smith, J., \& Baltes, P. B. (1989). Testing-the-limits and the study of adults age differences in cognitive plasticity of a mnemonic skill. Developmental Psychology, 25, 247-256.

Kornblum, S., Hasbroucq, T., \& Osman, A. (1990). Dimensional overlap: Cognitive basis for stimulus-response compatibility-a model and taxonomy. Psychological Review, 97, 253-270.

Lawhon, T., Ennis, D., \& Lawhon, D. C. (1996). Senior adults and computers in the 1990s. Educational Gerontology, 22, 193-201.

Lezak, M. D. (1995). Neuropsychological assessment (3rd ed.). New York: Oxford University Press.

McConatha, J. T., McConatha, D., Deaner, S. L., \& Dermigny, R. A. (1995). Computerbased intervention for the education and therapy of institutionalized older adults. Educational Gerontology, 21, 129-138.

McConatha, D., McConatha, J. T., \& Dermigny, R. (1994). The use of computer services to enhance the quality of life for long term care residents. The Gerontologist, 34, 553-556.

Mead, S. E., Batsakes, P., Fisk, A. D., \& Mykityshyn, A. (1999). Application of cognitive theory to training and design solutions for age-related computer use. International Journal of Behavioral Development, 23, 553-573.

Milgram, N. W. (2003). Cognitive experience and its effect on age-dependent cognitive decline in beagle dogs. Neurochemical Research, 28, 1677-1682.

Morrell, R. W., Mayhorn, C. B., \& Bennett, J. (2000). A survey of world wide web use in middle-aged older adults. Human Factors, 42, 175-182.

Pavot, W., Diener, E., Randall Colvin, C. R., \& Sandvik, E. (1991). Further validation of the satisfaction with life scale: Evidence for the cross-method convergence of well-being measures. Journal of Personality Assessment, 57, 167-176.

Robertson, I. H., \& Murre, J. M. (1999). Rehabilitation of brain damage: Brain plasticity and principles of guided recovery. Psychological Bulletin, 125, 544-575.

Rogers, W. A., \& Fisk, A. D. (2000). Human factors, applied cognition and aging. In F. I. M. Craik \& T. A. Salthouse (Eds.), The handbook of aging and cognition (pp. 559-591). NJ: Erlbaum Mahwah.

Schaie, K. W., \& Willis, S. L. (1986). Can decline in adult intellectual functioning be reversed? Developmental Psychobiology, 22, 223-232.
Sherer, M. (1996). The impact of using personal computers on the lives of nursing home residents. Physical \& Occupational Therapy in Geriatrics, 14, 13-31.

Slegers, K., van Boxtel, M. P. J., \& Jolles, J. (2009). The effects of computer training and Internet usage on cognitive abilities of older adults: A randomized controlled study. Ageing, Clinical and Experimental Research, 21, 43-54.

Stern, Y. (2002). What is cognitive reserve? Theory and research application of the reserve concept. Journal of the International Neuropsychological Society, 8 448-460.

Stern, Y. (Ed.). (2007). Cognitive Reserve: Theory and Applications. New York \& London: Taylor \& Francis.

Stigsdotter, A., \& Backman, L. (1995). Effects of multifactorial memory training in old age: Generalizability across tasks and individuals. Journal of Gerontology, 50B, 134-140.

Swaab, D. F. (1991). Brain aging and Alzheimer's disease, "wear and tear" versus "use it or lose it". Neurobiology of Aging, 12, 317-324.

Tak, S. H., Beck, C., \& McMahon, E. (2007). Computer and Internet access for longterm care residents: Perceived benefits and barriers. Journal of Gerontologica Nursing, 33, 32-40.

van Beijsterveld, C. E. M. van Boxtel, M. P. J., Bosma, H., Houx, P. J., Buntinx, F., \& Jolles, J. (2002). Predictors of attrition in a longitudinal cognitive aging study: The Maastricht Aging Study (MAAS). Journal of Clinical Epidemiology, 55, 216-223.

van der Elst, W., van Boxtel, M. P. J., van Breukelen, G. P. J., \& Jolles, J. (2005). Rey's verbal learning test: Normative data for 1855 healthy participants aged 24 81 years and the influence of age, sex, education, and mode of presentation. Journal of the International Neuropsychological Society, 11, 290-302.

van der Elst, W., van Boxtel, M. P. J., van Breukelen, G. P. J., \& Jolles, J. (2006). The letter digit substitution test: Normative data for 1858 healthy participants aged 24-81 from the Maastricht Aging Study (MAAS): Influence of age, education and sex. Journal of Clinical and Experimental Neuropsychology, 28, 998-1009.

Van der Elst, W., van Boxtel, M. P. J., van Breukelen, G., \& Jolles, J. (2006a). The concept shifting test: Adult normative data. Psychological Assessment, 18, 424-432.

Van der Elst, W., van Boxtel, M. P., van Breukelen, G. J., \& Jolles, J. (2006b). The Stroop color-word test: influence of age, sex, and education; and normative data for a large sample across the adult age range. Assessment, 13, 62-79.

van Hooren, S. A. H., Valentijn, S. A. M., Bosma, H., Ponds, R. W. H. M., van Boxtel, M. P. J., \& Jolles, J. (2007). Cognitive functioning in healthy older adults aged 64-81: A cohort study into the effects of age, sex, and education. Aging, Neuropsychology and Cognition, 14, 40-54.

Verghese, J., Lipton, R. B., Katz, M. J., Hall, C. B., Derby, C. A., Kuslansky, G., et al (2003). Leisure activities and the risk of dememtia in the elderly. The New England Journal of Medicine, 348, 2508-2516.

Ware, J. J. E., Kosinski, M., \& Keller, S. D. (1994). Physical and mental summary scales: A user's manual. Boston, MA: The Health Institute.

White, H., McConnell, E., Clipp, E., Branch, L., Sloane, R., Pieper, C., et al. (2002). A randomized controlled trial of the psychosocial impact of providing Internet training and access to older adults. Aging and Mental Health, 6, 213-221.

White, H., McConnell, E., Clipp, E., Bynum, L., Teague, C., Navas, L., et al. (1999). Surfing the net in later life: A review of the literature and pilot study computer use and quality of life. Journal of Applied Gerontology, 18, 358-378.

Wilson, R. S., Mendes de Leon, C. F., Barnes, L. L., Schneider, J. A., Bienias, J. L., Evans, D. A., et al. (2002). Participation in cognitively stimulating activities and risk of incident alzheimer disease. Journal of the American Medical Association, 287, 742-748. 